\title{
eLyra
}

REVISTA DA REDE INTERNACIONAL LYRACOMPOETICS

Franklin Alves Dassie

\section{JLG [excertos]}

\section{5}

Há um ano - mais ou menos - eu mandava uma mensagem $\mathrm{p} /$ você. Isso - de alguma forma

- tem relação com minha escolha de ver um filme do JLG numa quinta-feira de outubro quase um ano depois.

Gostaria de documentar minha "participação" na retrospectiva. Mas isso não seria um documentário.

Eu deixaria você sentar na janela já que o mar não é um hábito $p /$ você. Mas isso não seria um documentário.

\section{SALVE-SE QUEM PUDER (a vida)}

Cenas com o uso da câmera lenta:

Denise andando de bicicleta

A filha de Paul jogando bola

As mãos do tipógrafo na oficina do jornal

Paul se jogando em cima de Denise

Paul acidentado ao fim do filme

Nem a câmera lenta salvou a gente da gente 
Algum personagem diz: "Você não pode construir nada com um martelo". É claro, essa é uma afirmação polêmica de um polemista - que de alguma maneira é uma criança. Mas você pode, sim, construir algo com um martelo: um buraco num muro, por exemplo. Por ele passa um fiozinho de vento. Que alegria.

\section{COMING BACK HOME (dentro do ônibus)}

"No love / no problem / kill the noise"

\section{COMING BACK HOME (nas barcas)}

"Colete salva-vidas abaixo dos assentos". Traduzem "colete salva-vidas" como "life jackets". Eu penso em "coletes da vida".

\section{5}

Dizem-me por mensagem que eu tenho "uma paciência vaidosa ou que sou um carrinho de supermercado sem fundo". Entendi "paciência vaidosa" como o tempo da vingança. A coisa do "carrinho sem fundo" levei ao pé da letra mesmo.

As imagens mais interessantes de ontem não estavam nos filmes de JLG, mas na antessala da sala de exibição: a menina sentada no chão com uma tatuagem no braço esquerdo; as amigas que vieram de Belo Horizonte, a menina de óculos e franja, o senhor que bocejava bem alto antes do filme começar, o garoto com camisa punk e o celular com tela quebrada e as três amigas idosas vestidas - todas - de preto.

A expressão "paciência vaidosa" começa a fazer mais sentido. E se junta a uma frase que eu escutei numa música: "Eu sonhei com alguém tendo um ataque cardíaco".

Esse caderno deve ser da década de setenta. Pode ter a minha idade ou quase a minha idade. Pode ter a idade do senhor que bocejava. Já têm manchas de oxidação. 


\section{CHUVA / KARL MARX}

Chove e eu não tenho guarda-chuva como sempre. Um guarda-chuva é um objeto de circunstância. Choveu tanto que a letra R do letreiro Godard caiu. Li "god" e "dad" - mas não queria nem um nem outro perto de mim agora. Estou fazendo um documentário contemporâneo.

O guarda-chuva que comprei - porque chovia e eu não tinha guarda-chuva - já estragou. Não durou uma hora sequer.

Alguém na fila comenta: guarda-chuvas são objetos de circunstância, signo de muitos outros objetos descartáveis do mundo contemporâneo. Quase dei com o guarda-chuva-quebradosigno na cabeça dele.

A cor da pele da garota morena com vestido florida é uma cor bonita. Ela nunca ri.

Quem são as pessoas que assistem uma retrospectiva completa de JLG? Senhores e senhoras aposentados, jovens de vinte e poucos anos c/ camisas floridas, estudantes, mais aposentados, revolucionários em potencial, cineastas em potencial e pessoas perdidas. Identifico-me com todas elas. 


\section{TUDO VAI BEM (1974)}

"Cada um é seu próprio historiador". Agora sim tenho uma justificativa para continuar meu documentário.

Tudo vai bem foi realizado em 1974. Um ano depois do meu nascimento e 4 anos depois da revolução de 1968. Anoto isso tudo no McDonalds, que é uma fábrica de comida ruim. Duas meninas tomam um sorvete felizes da vida. Possivelmente apaixonadas.

A cena final de Tudo vai bem se passa num supermercado. A "narradora" diz que o supermercado é um "teatro social" - atores anunciando produtos e o público - os espectadores - assistindo tudo aquilo.

A cena é um plano longo - sem cortes - onde pessoas compram a mesma coisa - uma série de embalagens. A cor predominante das embalagens: amarelo. A fruta: laranja.

A personagem - que era esposa de JLG na época - liderava os saques. Mas nem ela nem ele imaginavam que - no fatídico ano de 2049 - os sacos plásticos que embalaram os produtos iriam deixar grande parte da população sem ar. Quem sabe essa seja a cena final do meu documentário contemporâneo-apocalíptico.

Respondi um e-mail, uma mensagem, estou voltando p/ casa.

"Supermercado", "teatro social".

Meu guarda-chuva não funciona mais. 


\section{CÂMERA-OLHO (1967)}

JLG escreve uma carta ao governo norte-vietnamita, pedindo autorização p/ filmar Câmeraolho em Hanói. Oito meses depois ele recebe a resposta: "O senhor tem uma ideologia um pouco vaga e isso não contribui muito na nossa luta". Uma "ideologia um pouco vaga". Godard concorda.

Estou com dor e cabeça. Lembro-me de outras coisas, mas não anoto.

"Mas se as bombas não caem em nós, filmá-las é algo abstrato". É um pouco vago filmar coisas abstratas.

Trabalhadores não assistem aos filmes de JLG. Nem grevistas. JLG preso numa prisão cultural, trabalhadores presos numa prisão econômica.

\section{AQUI E ACOLÁ (1974)}

Em casa penso em algo que ouvi nesse filme: "Abandonar o sistema de perguntas e respostas".

Uma cena é quando a gente vê quem está em cena, mas não vê quem dá as ordens.

A voz de Aqui e acolá transcrita mais ou menos: Não conseguimos ver imagens simples, uma vez que o som está sempre alto e cobre a realidade - o som alto borra as imagens simples. É isso.

Pergunto-me: o que seria esse "som alto".

Queria fotografar você, mas não seria legal fotografar você sem você saber que eu fotografava você.

Esse "som alto" pode ser uma pessoa?

Meu guarda-chuva, que parou de funcionar em menos de dez minutos, foi fabricado na China. Li na etiqueta. 


\section{5}

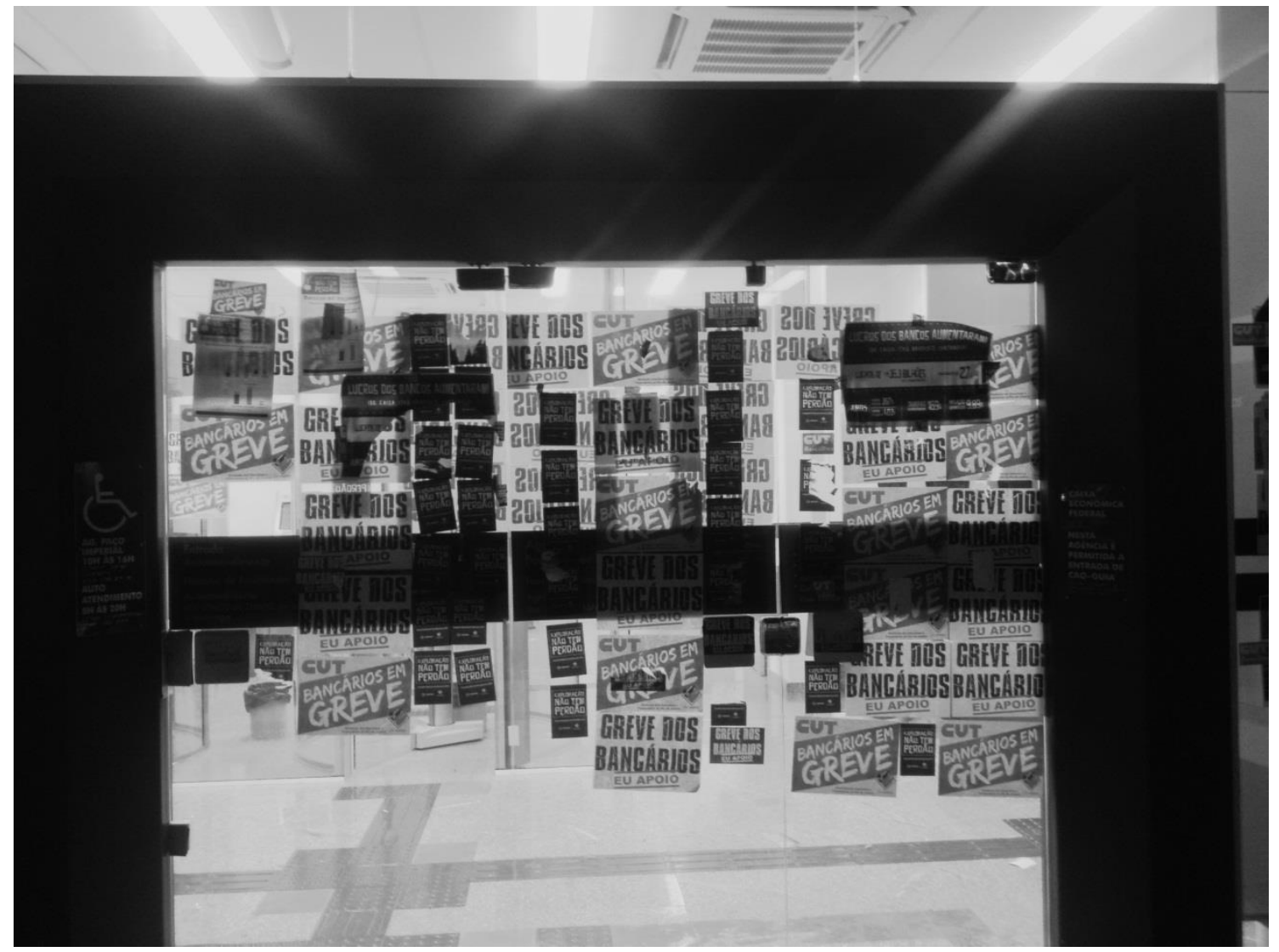

Entre as greves fílmicas, me deparo com uma greve de verdade. Mas os cartazes de verdade estão colados em um espaço que parece uma tela.

Em Tudo vai bem os personagens são entrevistados como em um documentário. Eles trabalham em uma fábrica de produtos alimentícios e estão em greve.

g-r-e-v-e 


\section{G-r-a-v-e}

Mais de cento e vinte dias sem te ver. Cento e vinte e dias é quase o nome de um filme. Cento e vinte dias poderia ser o nome de um documentário.

Podem dizer que escrevi isso tudo $\mathrm{p} /$ esquecer você. Tudo bem, essa pode ser "a função" disso. Escrever alguma coisa, um livro, fazer um documentário para esquecer outra pessoa. Muito válido.

Dormir é um problema $\mathrm{p} / \mathrm{mim}$

Palavra: Adorable

Outra palavra: hable

Era complicado dormir com você porque eu não podia encostar sem querer em você quando você dormia. Daí o problema de dormir se transformava num problema duplo. Como dormir atento? Um problema bem maior do que já era. Um monstro.

Acho que uma hora serei "engolido" por essa ideia de escrever um documentário sobre JLG. Aliás, acho que é assim que faço qualquer coisa - quando "engolido" por essa qualquer coisa. 